DOI: doi.org/10.21009/IJLECR.071.09

Received: 21 July 2020

Revised: 21 December 2020

Accepted: 18 June 2021

Published: 30 June 2021

\title{
GOFOOD AND GOJEK APP: FORM OF TRAVERSAL WORLD DOMINATION
}

\author{
Sri Kusuma Winahyu ${ }^{1, a)}$, Yumna Rasyid ${ }^{2, b)}$ \\ Agency for Language and Book Development, Ministry of Education and Culture, Jakarta, \\ Indonesia $^{1)}$, State University of Jakarta, Indonesia ${ }^{2)}$ \\ sriwinahyu0406@gmail.com ${ }^{\text {a)}}$,yumna.rasyid@unj.ac.id ${ }^{\text {b) }}$
}

\begin{abstract}
Social life always presents endless discourse of phenomenon. In the era of the birth of Generation $\mathrm{Z}$, also born the fact that traversal world has started to become a "new footing" in human life. Beginning with traditional text forms, multimodal text, and hypermodal texts, hypertext is now so massively developing in society. Without realizing, It is able to build power over its users. This power is reflected in layers of links that are read through hypertext semiotic classifications. This study discusses the hypertextualized Gojek online applications with their content, Gofood. This application is part or example of the traversal genre. The hypertext semiotic which was initiated by Lemke based on hypertext semantic analogy by Halliday, carried out at the first discussion stage. Furthermore, data analysis was carried out using Fairclough's critical discourse analysis as a transdisciplinary analysis stage in the second discussion. The results of the study show that the form of dominance of the power of this online application that can be seen from the meaning of its semiotic classification, namely presentational, orientational, and organizational. Meanwhile, the relationship that appears from the application with social life clearly shows that the traversal world has dominated and control the lives of today's people.
\end{abstract}

Keywords: multimodal, hypermodal, traversal genre, hypertext semiotics, critical discourse analysis

The excitement of human life without being felt has been so advanced. There is something invisible, but in reality it controls the daily routine of modern society. When it arrived at the time of the presence of mobile devices and sophisticated virtual applications, then it was so easy for someone to communicate with others, including getting various kinds of services, just by touching the cellphone screen. This is one of the demands of the 4.0 disruption era, the era of the birth of generation $\mathrm{Z}$.

That period actually began at around ten years ago, namely in 2009. The Blackberry (BB) technology was able to "summarize" internet activities (with quotas) that were originally done exclusively on computers, such as accessing Google, opening e-mail, and opening Facebook. Even so, what is done in BB technology is just updating some older technology. For example, It still uses the old keypad or "qwerty". Then, came the advanced touchscreen technology by the presence of Apple with IOS. However, Google, which is a search engine, or also the widest search-ended WorldWideWeb (www) in the world, then bought touchscreen company technology with Android as its content (Android is equivalent to the functionality of iOS owned by Apple). At the same time, 
Samsung then uses Android technology with Google as one of its contents. Samsung with its Android content (also automatically has Google in it) is then massively used in Asia. In terms of price, Samsung has a wider range, from expensive to cheap, so it is very common in Asia that has a high consumption consumption market. On the other hand, a very strategic and profitable side, Google is increasingly developed with open-ended WorldWideWeb (www) which is able to control the world with Android.

Such developments make the business world began to take advantage of both. Online applications appear, including Tokopedia, Bukalapak, Uber, Grab, and Gojek. Such companies, even individuals are competing to make applications with internet vehicles and Google templates so it is very easy to run with Android. This is one form of world power crossing in the era of disruption. Hypertext, especially open-ended hypertext like www, for example Google, provides a great opportunity for the emergence of new genres (Lemke, 2005). This genre is not in accordance with the general genre, but rather more interesting, even satisfying, and tends to be utilized maximally as a traversal template, one of which is the presence of the Gojek application.

The emergence of content in virtual applications as stated earlier has begun through the emergence of multimodal texts. The power of visual communication becomes many times when deployed together with languages in multimodal texts (Lemke, 2002, p. 299). In its journey, multimodal developed into hypermodal. In hypertext, like websites, the interaction of two semiotic sources provides a new form of information and the complexity of design, and provides new political choices.

Hypermodality according to Umberto Eco (Lemke, 2002, p. 299) opens our minds that imitation reality is more interesting than everyday life. Hypermodality is more than multimodality, hypertext is more than just plain text. In the simplest form of hypertext, web pages (which may contain paragraphs, sentences, even words) as a whole or some parts are connected to the whole or part of another page (or other parts on the same page). It is very different from the convention of reading plain text. The existence of a link makes hypertext multisequential.

According to Arnheim (Lemke, 2002, p. 300), in multimodal there are many sources of visual significance in a page, such as tracing our views on images or diagrams according to the characteristics and vectors that connect them. There we can take our eyes away from the closest and the farthest words and those that stand out because of the font type (italics, bold, lowercase letters, etc.) or the ease of recognizing (eg showing certain names or key words that are interesting ) It could be because the words are the header or sidebar, or are the words beginning or end of a paragraph or section.

Meanwhile, in the context of hypermodal, hypertext medium characterizes different things. Aside from being different (more advanced) technology, web connectivity from a hypertext involves links out of the text unit itself. There will not be a single standard reading sequence from the main text to return to the text. In hypertext there is only sightseeing / surfing (trajectory) trajectory and rotation on different scales, without one unifying narrative or sequential development of the thesis, as in traditional texts.

The multimodal world was also studied by O'Halloran (K. O'Halloran, Tan, Smith, \& Podlasov, 2010) about the design of digital interfaces for the study of multimodal phenomena; (K. L. O'Halloran, 2008) regarding systemic multimodal functional discourse (SF-MDA) analysis that criticizes ideational meaning using language and visual imagery; and (K. L. O'Halloran, Tan, Smith, \& Podlasov, 2011) about multimodal analysis in an interactive software environment that uses a critical discourse perspective. In addition, another researcher who also studied multimodal is Yingen Xiong (Xiong \& Quek, 2006) which discusses the frequency of hand movements with oscillation frequency extraction of hand movements accompanying speech using multimodal discourse analysis. 
Anthony Baldry and Paul Thibault (Anthony Baldry, Paul J. Thibault, 2007) present a course book on transcription and multimodal text analysis, rooted in Halliday's semiotics, which connects monographs to the work of Gunther Kress and Theo van Leeuwen (2009). They took a variety of 'semiotic systems' which formed multimodal texts consisting of language, movement, and music which were also quoted by Lemke to begin his discussion of hypermodal (Lemke, 2002). Specifically concerning multimodal in multimedia framework also discussed by Silva (Silva, Assis, \& Pereira, 2014); Stamou (Stamou \& Paraskevopoulos, 2006); Mukanova (Mukanova, 2012).

Many multimodal or hypermodal studies are also associated with critical discourse analysis so that it becomes a transdisciplinary study. Cukier, et al. (Cukier, Ngwenyama, Bauer, \& Middleton, 2009 , p. 175) criticize the discourse of information technology media using Habermas' critical discourse analysis (CDA). His research resulted in a discussion of the impact of systematically distorted communication of critical reflection about technology in the public space. The hypermodal transdisciplinary study and critical discourse analysis also penetrated the field of food systems. The field of food systems or food systems is seen as a new discipline which contains certain characteristics, philosophical, and methodology. This field was also assessed as a transdisciplinary field because it crossed borders and brought researchers to various study areas. The food system is part of the discourse and thick involves the social realm that appears from posts on social media and audience questions (Grohman, 2016, p. 3). Meanwhile, Schaenen (Schaenen, 2010) discusses the development of genres and focuses on the multimodal analysis that he uses using critical discourse analysis.

AWK / CDA, which increasingly touches the social and political realm, also analyzes the problem of marketisation of public discourse in contemporary England, especially higher education (Norman Fairclough, 1993). The discussion is related to capitalist society with a discussion of the value of critical discourse analysis as a method in scientific social research, and as a resource of social struggle. Meanwhile, AWK / CDA in the digital era was also used to analyze US cities' wireless networks to improve social inclusion (Tapia, Kvasny, \& Ortiz, 2011). The strength and ideology of everyday discourse was also reviewed by Morley (Morley, 2004).

This study discusses Go-Food in the Gojek application as a form of hypertext discourse and relates it to the power of crossing both in the political and social realm during the present generation of Generation Z, especially in Indonesia, as a form of transdisciplinary analysis.

\section{METHOD}

This study uses qualitative methodology with in-depth observations of existing data. In qualitative methodology, researchers look at systems and individuals holistically and emphasize the meaning of research. Qualitative research requires expertise and skills (Miles, Huberman, \& Saldaña, 2014 in Taylor, 2016). Qualitative researchers are flexible in conducting research and are encouraged to become experts with their own methods.

\section{Traversal Genre}

Genres are traditionally text types. The text has its own characteristics and can be identified as a differentiator from one another. These characteristics can be seen from the content of the text, for example the character wants to know about detective stories, characters offer or persuade advertisements, or characters in the form of certain stages in the procedure text (Lemke, 2005).

The emergence of hypermodal and hypertext texts is a study of the genre of crossing. One characteristic of the traversal genre is the possibility of a combination of textual items (on any text scale) with all visual features that might never be the same. Not always a text (writing / verbal) related to one image (imagetext) or vice versa. In addition, there is a view that the overall information in each imagetext in general is always far less than the verbal text. However, in 
hypertext, it is just the opposite. Linkages between images and text or images with images through existing links give rise to the possibility of very broad meanings. For this reason, it is necessary to read or interpret certain meanings as proposed by Lemke (Lemke, 2002), namely semiotic schemes to analyze composite verbal-visual meanings and some discussions of semiotic politics of visual communication in hypermedia design.

The above scheme is first divided into three types of meanings made by each semiotic action, namely presentation, orientation, and organization. Then consider how the meanings are based on the markers in different signs. For example, systems (language, images, music, etc.) can be combined or integrated to produce new, more specific types of meanings that were not initially available. These principles are illustrated by analyzing several pages of the website and then concluding with some hypermedia design political issues. Following are the presentation criteria, orientation, and organization.

\section{Presentational}

Presentation is the main thing from ideational text content. Kress and Van Leeuwen, 1996 (Lemke, 2002) suggest that content contains processes, relationships, events, participants, and circumstances. For images, one can apply the same term, recognize what is displayed or illustrated, whether figural or abstract.

Meanwhile, according to Halliday, 1994 (Lemke, 2002) presentational is a link that binds a set of topics specific semantic relations with others internally, for example the activities of $\rightarrow$ actor, object $\rightarrow$ quality, event $\rightarrow$ form, etc. Logical expansion relationships and projections in the form of restatements, specifications, examples, comments, exceptions, alternatives; conditionality, causality, contextualization; quotes, opinions are also part of presentational. Presentation is also a rhetorical relationship which then determines logical relationships, including concessions, opposition, disjunctions, problems-solutions, causes, proposals, and generalizations of Mann and Thompson, 1986 (Lemke, 2002).

\section{Orientational}

The meaning of orientation shows the audience what is happening in communicative relationships and what attitudes may be held by participants with each other and the presentation content. With this meaning people are oriented towards each other in actions and feelings, and to the community of these people in terms of points of view, attitudes, and values. In the text, someone is oriented towards a communication situation, especially in terms of speech and exchange actions: are there offers or demands? Are there treatments intimate or distant, respectful, or disparaging? Actual signs range from clauses (interrogative, imperative) to modalities. Visually, there is also a communicative or rhetorical relationship in which the image mediates between the creator and the viewer and projects the attitude or point of view of the viewer and the content presented in the image.

\section{Organizational}

The meaning of the organization is largely instrumental and has a background that allows two other types of meanings to achieve greater levels of complexity and precision. Basically, organizational resource meaning allows us to create and know other signs that together become larger units. This unit is a structural unit, which is contiguous in text or image-space, and usually contains elements that are distinguished in function (subject / predicate in clauses and / or foreground / background in the composition of images). Organizations are cohesive chains, which can be distributed to the next to each other, and where similarities and contrasts in common features tie together a longer stretch of text or a larger level of image as a whole or whole. 
Organizations are seen as functional relationships between structural elements such as: nominal groups, clauses, complexes, rhetorical formations, and genres (Halliday, 1994; Martin, 1992 (Lemke, 2002)). In this connection there are chain elements of covariates, namely similarity chains, co-hyponymic chains, comeronymic chains; based on presentation or orientation features. When we proceed from Lexia to Lexia along the traversal, each pair that is connected may have many of the relationships above. For each semantic connection, there are principles and visual forms that are appropriate. In fact, many of the verbal relationships can be conceptualized as visual metaphors.

The analogy of what is called long-scale text semantics in the form of more conventional verbal media applies in this context. Semantic hypertext in this case is the affordability of hypertext mediums to build meaningful relationships along traversal. Just as making meanings in many paragraphs or chapters that are not made in a paragraph or chapter, the meaning in hypertext can be made along long crossings with links. In essence, there are basic things, namely (1) that meaning is made through the insertion of structures on different scales, especially the structure of the genre and the rhetorical-argumentative structure; and (2) that meaning is also made through an extended chain of cohesion (Halliday and Hasan, 1976, (Lemke, 2002)) and by crossing (traversal) both in a much shorter structure and scale of text (Lemke, 1995 (Lemke, 2002)).

In hypertext networks that are rich in interconnection, it is possible to use structures like genres, but it is difficult to hierarchically arrange them sequentially. The chain of cohesion based on the relationship of unit similarity throughout the text works equally well in hypertext. It is possible for hypertext readers to gradually collect many details and models from those drawn as well as those obtained from ordinary narratives or novel texts.

\section{Critical Discourse Analysis}

Fairclough's formulation of the scope of the critical discourse analysis (CDA) is to develop ways of analyzing languages that address his involvement in the sphere of modern capitalist society (N. Fairclough, 2010, p. 14). In the scope of modern capitalist society it is evident that there is what is called power, which is something that guides and even demands the community to directly or indirectly follow it and there are times when it depends entirely on that power.

Proxy is a misalignment of the participants in the discourse; unbalanced capacity to control how the text is produced, distributed and consumed (Fairclough 1995, pp. 1-2). To see the power reflected in a discourse, Fairclough (1995, p. 97-98) suggests three dimensions of discourse, namely text, discourse practice, and sociocultural practice.

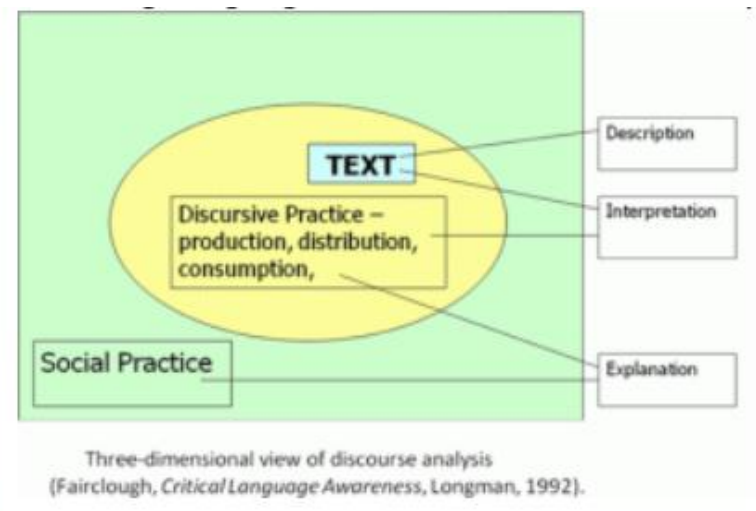

Scheme 1: CDA Dimensions

The text is analyzed linguistically. All the elements analyzed (vocabulary, semantics, sentence order, cohesion, and coherence) are used to see three problems, namely ideational, relations, and identity. Ideational in this case refers to the desire to see how something is displayed in the text that 
might carry a certain ideological charge. Relation refers to the analysis of how the relationship between the ruler and his partner (reader / user community) is constructed, for example, whether the text is delivered formally or informally, open or closed. Identity refers to certain constructions of the identity of the ruler / application and the user.

The discourse dimensions in Scheme 1 were analyzed using the dimensions of discourse analysis, namely description, interpretation, and explanation. The description stage includes analysis of language data (vocabulary, grammar, and textual structure) that concerns experience, relational, and / or expressive values. The stage of interpretation is the process of connecting between what is in the text and what is in the mind of the interpreter (researcher). The focus of interpretation is the relationship of context to text and how the intentions are disguised in the text. Explanation stage is the process of connecting between text and social situations. This is aimed at photographing discourse as a social process by examining the structure of relations between powers.

In its development, discourse analysis that also touches the political realm requires proliferation, not narrowing (Hay, 2013, p. 321). This was a critical debate with Fairclough and Issabella who then answered it by discussing the nature of politics as one of the CDA perspectives (I. Fairclough \& Fairclough, 2013).

Along with the development of cases and the complexity of the human mindset, ways of operationalization of discourses have also developed. The operational of discourses shows how and what the subject conditions of discourse are operationalized as strategies and implemented into practices that are changed from action and interaction; instilled in the change in the way to become an identity; materialized in changes to material reality. Operationalization is a process in discourse or semiosis, where discourse is determined as a genre change, and is embedded as a changing style. The dimensions of discourse analysis to analyze the things in which discourse contributes to social transformation, the focus also extends to the relationship between discourse and other social elements (such as relationships that are part of discourse or semiosis) and therefore, become a problem for critical transdisciplinary analysis. However, the process always pushes back within the framework associated with different forms of social critical discourse (CDA) analysis, to analyze the relation between discourse and other elements (N. Fairclough, 2010).

The data source of this research is Gofood application specifically and Gojek in general. Semiotic hypertextual analysis method is used for images and links that connect with more in-depth information. In addition, critical discourse analysis is used as a transdisciplinary critical analysis of language use content in Gojek and Gofood online applications. However, due to the breadth of the links within the application (it can reach dozens and branch into hundreds of links), restrictions are made only on the main part of the Gojek application content and enter the Gofood link.

\section{RESULTS AND DISCUSSION}

\section{Hipertekstual Semiotics}

There are nine display application content, namely two on Gojek and the rest of Gofood. Because Gofood is one part of the link in Gojek, the discussion begins with the parent, namely Gojek. The Gojek icon in figure 1 uses black as a background and green writing and the use of capital letters. This icon is part of the presentational meaning of contextualization, namely in terms of choosing the name "Gojek". Then, organizationally this link opens the Gojek application and contains a cohesive chain that binds one link with the next links in the link marked with the Gojek icon. 

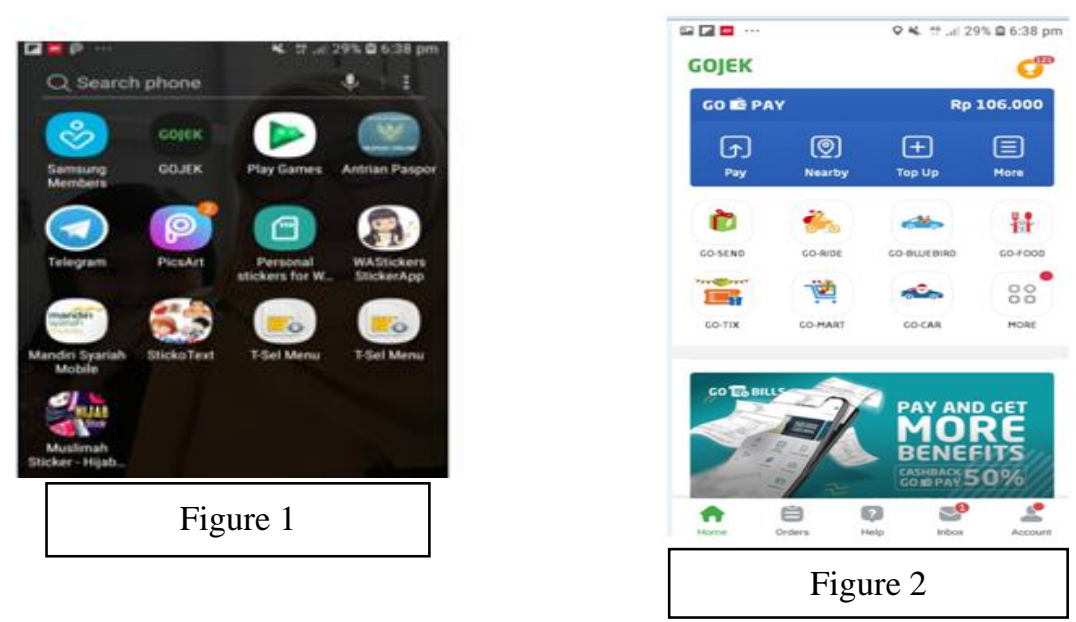

Figure 2 shows the contents of the Gojek application which contains the Gopay link which also contains pay, nearby, topup, and more links. Gopay Link with its own content is about payment facilities. Next is the Go-send link, Go-jek, Go-bluebird, Go-food, Go-tix, Go-mart, Go-car, and more (Go-other). Then, there is the Go-bills link in the section down and patent links in the form of home, orders, help, inbox, and account. The names of the links contain the presentational meaning of contextualization, while the images the link contains figural presentational meaning, that is, using icons that describe the service in question.

In addition, the links in Figure 2 orientatively invite users to interact. The links which are services that provide intimate treatment to the user invites to interact with the convenience of any Go-service. From Go-pay, there are easy payments compared to cash payments; then Go-send makes it easy to send documents and goods; Go-jek facilitates the mobility of users delivered by motorbike; Go-bluebird makes it easy for users to order a bluebird taxi without a payment meter; Go-food makes it easy for users to order food; Go-tix makes it easy for users to book cinema tickets; Go-mart makes it easy for users to shop; and the Go-car makes it easy for users to order taxis online on private non-meter number plates. Finally, Go-bills, offer the convenience of a pricecut deposit. It also appears that overall picture 2 is the iconic images that mediate the creator of the application and service provider to the Gojek application users. All links organizationally form cohesion with the contents of each link when clicked.
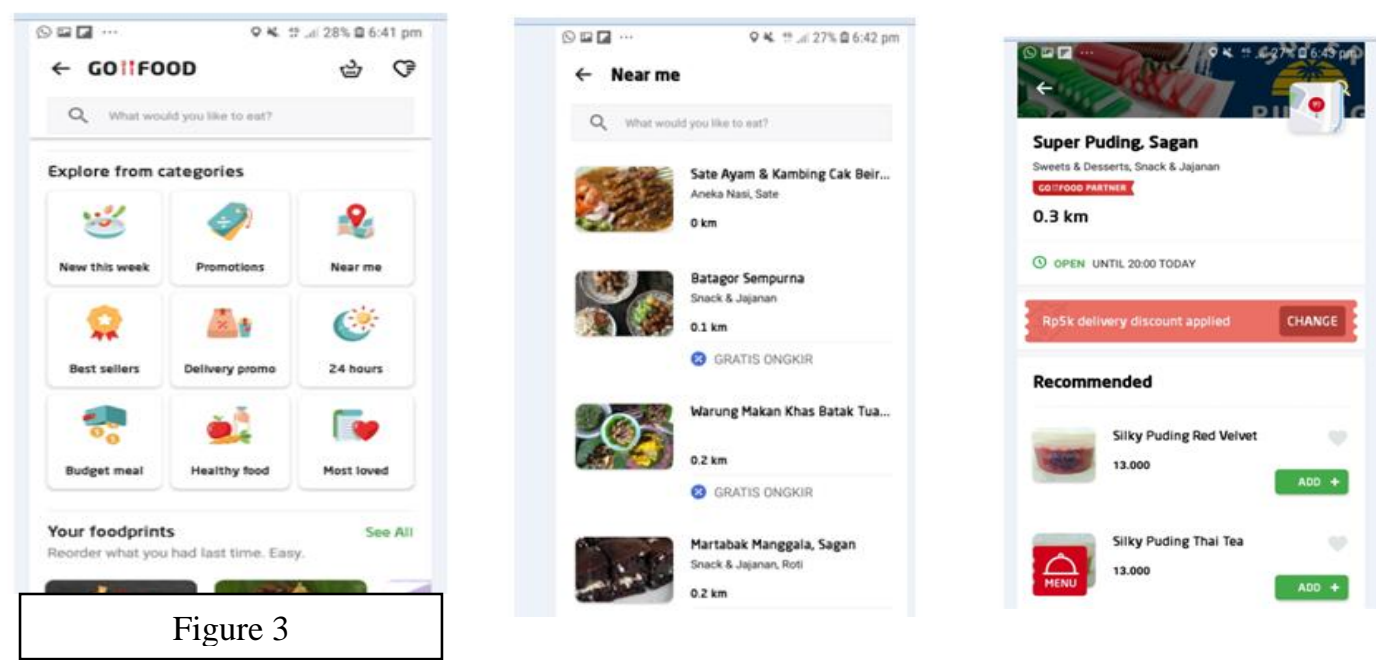
Figure 3 enters Go-food content after clicking the Go-food link in the previous image. In this content the orientational meaning looks more profound than before. Content with the title Explore from categories offers nine links all of which converge closer to objects and subjects, namely categories of food types and tailored to consumer desires.

New this week link contains the latest food menus every week. Promotion links contain restaurants or food stalls that offer discounted promo packages. Near me links are restaurant links or food stalls that are close to the user's location. Best seller links are the best-selling foods. Delivery Delivery promos contain restaurants or food stalls that provide promos on delivery orders. The 24 hour link is a link that contains restaurants or food stalls that are open 24 hours. Link Budget meal is a food provider that is relatively cheap. Healthy food links contain healthy foods such as juices, fruits, salads, and so on. Most loved links contain foods that are most liked or liked by Go-food users. These nine links contain presentational meanings other than figural images and service words / titles (presentational contextualization), also on logical relations of activity $\rightarrow$ actor, which concerns the subject namely service users and objects $\rightarrow$ quality, which concerns food in each link. Of course, these links also contain organizational meaning because when clicked will link back to more specific services (cohesive chain). After the Go-food link Near me is clicked, the user is connected again with Near me content as shown in Figure 4. In this link (Figure 4) there is a presentational meaning in the form of an object $\rightarrow$ the quality is increasingly conical with the figural display of real food image content (in the form of photos, not icons). In addition, there are orientational meanings in the offerings through existing images and organizational meaning because of the cohesive chain relationship with the content of each link.

When one of the Go-food links Near me in Figure 4 is clicked, it will be connected with Gofood content Near me as shown in Figure 5. Only then in this content the user places an order by clicking add. This is a form of orientational meaning, in which users are welcome to choose the menu they want through specific offerings of real images (manifestations of the presentational meaning) of the food menu. Meanwhile, organizational meaning is found in Add, which links it with order information and the total order price listed in each image.
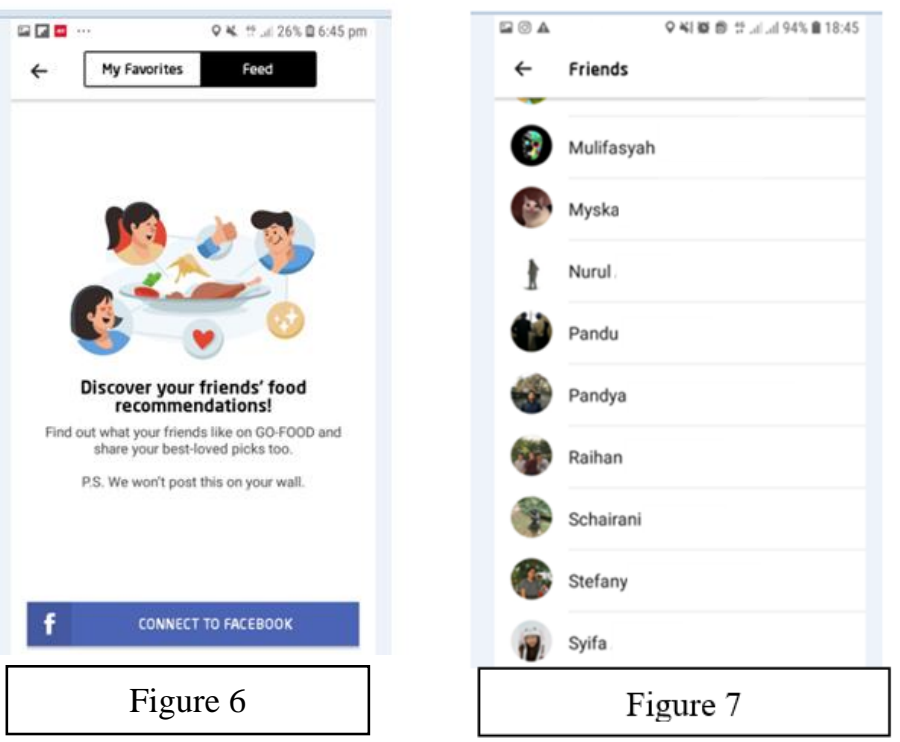
Figure 6 shows Go-food content that is related to Facebook, while Figure 7 is the names of friends who are friends with each other on Facebook and use (often order food through) Go-food. These two images show organizational existence because they contain a cohesive chain in which Figure 7 is the line of friends referred to in Figure 6. However, this does not automatically occur. There is an offer (orientational) process from the phrase Discover your friend's food recommendation! (which is also the presentational meaning of contextualization) in Figure 6 . If the user approves it, then clicks on the Feed link on the top right, organizational with picture 7 will occur with the appearance of the names of friends from the user's Facebook.

Furthermore, if the user has clicked on Feed in Figure 6 above, besides the organization will appear with Figure 7, something similar to the appearance of Figure 8. Schairani also occurs, for example, one of Facebook's users who also ordered food through Go- food, appears to upload the ordered food as shown in Figure 8. The verbal sentence that links it (becomes an organizational sign) is in Figure 6, which is Find out what your friends like on GO-FOOD and share your bestloved picks too. P.S. We won't post it on your wall. Here Schairani has shared the food she likes (share your best-loved picks). The sentence also marks the presentational meaning of contextualization.
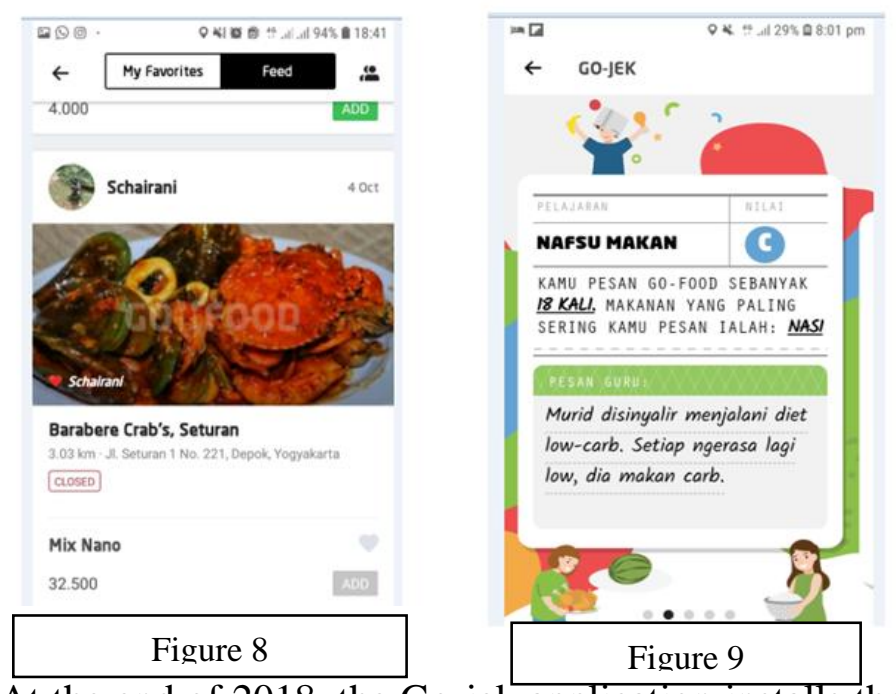

At the end of 2018, the Go-jek application installs the service usage report link. The content is as if the user is a student and the Go-jek application is school. Figure 9 shows an organizational report with overall Go-food services. Here there appears presentational meaning in the form of activity $\rightarrow$ actor. The activity is indicated by the Go-food message clause 18 times in the sentence You ordered Go-food 18 times and the sentence The food you order most often is: rice. Meanwhile, the actor here is your pronoun, the subject of the student in the sentence. underwent a low-carb diet, and her pronouns in the sentence Every time I feel low, she eats carb. Both of these markers (activities and actors) are both within the scope of the contextualized prestige meaning.

\section{CDA Dimension: Production and Consumption}

From the look of the manufacturer (Gojek / Gofood application service provider) there is a presentational meaning of contextualization that is rich in ideational values, namely (1) the choice of the name "Gojek" and (2) the selection of Go-send, Go-jek, Go-bluebird, Go -food, Go-tix, Gomart, Go-car, Go-pay, Go-bills. Meanwhile, relational values in presentational meanings appear in (3) the use of word choices Explore from categories, New this week, Promotions, Near me, Best sellers, Delivery promos, 24 hours, Budget meal, Healthy food, Most loved; (4) use of the phrase Discover your friend's food recommendation! Find out what your friends like on GO-FOOD and 
share your best-loved picks too. P.S. We won't post it on your wall; and (5) the use of the sentence you ordered Go-food 18 times. The food you order most often is: rice. Students allegedly underwent a low-carb diet. Every time I feel low, he eats carb.

In addition, there are orientational meanings that contain relational values, namely (6) services and offers that generally invite users to interact through "Go-whatever" links that provide intimate / close treatment to users with ease of service. Then, the organizational meaning that shows ideational value, namely (7) hyperlink links that form a cohesive chain as a whole, tight, broad, and deep (conical). Finally, the identity value is in (1) - (7).

On the consumption side, namely the response from the user, there is a presentational meaning in the form of (8) figures of preferred food images uploaded and connected intertextually with Facebook. In addition there are also organizational meanings in the form of (9) hyperlinked links with Facebook through the names of Go-food applications. Presentational (8) and organizational meaning (9) both show relational value.

\section{Interpretation: Production and Consumption}

From the point of view of word selection and experience value, (1) is the acronym of Go + Ojek $\rightarrow$ Gojek, where the word go grammatically has several meanings including 'go' or 'ride'. However, metaphorically go can be interpreted as an invitation, such as 'let's go' so that it can become a 'motorcycle ride' ride. On the other hand, in Javanese, there is the word gojek which means 'joke' or 'joking'. The spirit of joking and being happy with riding motorbikes coloring the beginning of this online motorcycle taxi application.

When Gojek develops into extensive services (not just motorcycle taxis), there are broad meanings from ideational values. Not just riding a motorcycle taxi, the invitation is also to take advantage of other services available. This changes the experience value to expressive value and go metaphor from 'come' to 'fast' so that (2) the impression is that using "Go-whatever" must be faster.

Furthermore, the relational value at (3), (4), and (5) shows the relationship of the Go-jek application power to the user / consumer through the use of English sentences (at (3) and (4)), and further clarified with the use of Indonesian (on (5)). Contradiction (3) and (4) with (5) are seen, namely when (3) and (4) the context is that Go-jek views all users as understanding English, but when (5) Go-jek "realizes" that the user is an Indonesian speaker. Even so, (5) it is actually proof of the growing power of the application above the users.

Relational value at (6) so too. With the ease of exceptional service at (6) the power of this application is very visible above its users. Meanwhile, ideational value seems to be the ultimate weapon of this application in instilling the ideology of convenience that becomes a package in the Gofood application service in Gojek. Finally, overall, the identity value shows the construction of traversal in the form of Gofood specifically and the online application of Gojek in general which controls the user.

Based on interactional conventions in structural studies, (8) and (9) show a kind of stimulus and response which, when aligned with verbal text, is like a dialogue. The stimulus is provided by the Gofood service and the response is given by the user. Here it is increasingly apparent that the Gojek online application generally has the power to "dictate" its users.

\section{Explanation}

Regarding the social situation, there is no doubt that Gojek and Gofood really offer extensive convenience in one application. Even more remarkable that it turns out that convenience is captured, accepted, even needed massively by the user community.

Indeed, in the beginning if considering the presence of the first Gojek in the capital city of Jakarta and subsequently gradually in other regions, chaos struck simultaneously even for a 
moment. Conventional ojek and public transport companies protest. The Ministry of Transportation was also overwhelmed. However, in accordance with the "concordance" as well as the "sophistication" of the information world, the system that plays in the online application information technology turns out to be unable to be rejected by the public, and even in great demand. So, "defeat" the world of transportation business to the sophistication of systems and information technology. This is one sign of the power of the crossing world (traversal).

\section{CONCLUSION}

From the discussion above it appears that the results of semiotic hypertextual analysis classify the meanings of hypertext content in layers. In the advanced analysis using the AWK framework, the form of dominance of the power of online applications, namely Gojek (and Gofood in it), appears from the meaning of the semiotic classification, namely presentational, orientational, and organizational. The dominance of power that appears in this application clearly raises the ideology of application users within the framework of the world information technology system concept crossing the scope of the application. Here, the world of crossing turns out to control the pulse of today's society.

\section{REFERENCES}

Anthony Baldry, Paul J. Thibault, E. 2007. Multimodal Transcription and Text Analysis: A Multimedia Toolkit and Coursebook. Journal of Pragmatics, 39(6), 1235-1238. https://doi.org/10.1016/j.pragma.2007.02.007

Cukier, W., Ngwenyama, O., Bauer, R., \& Middleton, C. 2009. A Critical Analysis of Media Discourse on Information Technology: Preliminary Results of a Proposed Method for Critical Discourse Analysis. Information Systems Journal, 19(2), 175-196. https://doi.org/10.1111/j.1365-2575.2008.00296.x

Fairclough, Norman. 1995. Critical Discourse Analysis: The Critical Study of Language. London: Longman.

Fairclough, I., \& Fairclough, N. 2013. Argument, Deliberation, Dialectic and The Nature of The Political: A CDA perspective. Political Studies Review, 11(3), 336-344. https://doi.org/10.1111/1478-9302.12025

Fairclough, N. 1993. Critical Discourse Analysis and the Marketization of Public Discourse: The Universities. Discourse \& Society, 4(2), 133-168. https://doi.org/10.1177/0957926593004002002

Fairclough, N. 2010. Critical Discourse Analysis: the Critical Study of Language Norman Fairclough. [electronic resource] - Version details - Trove (Second Edi). London and New York: Routledge. Diambil dari https://trove.nla.gov.au/work/31052813?q\&sort=holdings+desc\&_=1539514208278\&versionI $\mathrm{d}=208016386$

Grohman, H. 2016. What We Talk About When We Talk About Food Systems : Discourse in an Emergent Field. University of Vermont ScholarWorks @ UVM, (Food Systems), 1-14. Diambil dari http://scholarworks.uvm.edu/fsmpr

http://mahetaarati1315.blogspot.com/2014/09/topic-what-is-discourse-and-discourse.html

Hay, C. 2013. Political Discourse Analysis: The Dangers of Methodological Absolutism. Political Studies Review, 11(3), 321-327. https://doi.org/10.1111/1478-9302.12026

Lemke, J. L. 2002. Travels in Hypermodality. Visual Communication, 1(3), 299-325. https://doi.org/10.1177/147035720200100303

Lemke, J. L. 2005. Multimedia Genres and Traversals. Folia Linguistica, 39(1-2), 45-56. https://doi.org/10.1515/flin.2005.39.1-2.45 
Morley, J. T. 2004. Power and Ideology in Everyday Discourse : The Relevance of Critical Discourse Analysis in Pragmatic Linguistics Today, 25, 20-25.

Mukanova, G. K. 2012. International Relations Around Central Asia, The Media Coverage : Critical Discourse Analysis ( Kazakhstan, the line XX - XXI centuries ).

O’Halloran, K. L. 2008. Systemic functional-multimodal discourse analysis (SF-MDA): Constructing ideational meaning using language and visual imagery. Visual Communication (Vol. 7). https://doi.org/10.1177/1470357208096210

O'Halloran, K. L., Tan, S., Smith, B. A., \& Podlasov, A. 2011. Multimodal analysis within an interactive software environment: Critical discourse perspectives. Critical Discourse Studies, 8(2), 109-125. https://doi.org/10.1080/17405904.2011.558687

O’Halloran, K., Tan, S., Smith, B., \& Podlasov, A. 2010. Challenges in designing digital interfaces for the study of multimodal phenomena. Information Design Journal, 18(1), 2-21. https://doi.org/10.1075/idj.18.1.02hal

Schaenen, I. 2010. Critical Inquiry in Language Studies " Genre Means ...": A Critical Discourse Analysis Of Fourth Grade Talk About, (December 2014), 37-41. https://doi.org/10.1080/15427580903523581

Silva, G. D., Assis, G. T. De, \& Pereira, A. C. M. 2014. SAPTE : A Multimedia Information System to Support The Discourse Analysis and Information Retrieval. https://doi.org/10.1007/s11042-014-2311-9

Stamou, A. G., \& Paraskevopoulos, S. 2006. Representing Protected Areas : a Greek Travel Magazine, 449, 431-449.

Tapia, A. H., Kvasny, L., \& Ortiz, J. A. 2011. A Critical Discourse Analysis of Three US Municipal Wireless Network Initiatives for Enhancing Social Inclusion. Telematics and Informatics, 28(3), 215-226. https://doi.org/10.1016/j.tele.2010.07.002

Taylor, Steven J., et.al. 2016. Introduction to Qualitative Research Methods: A Guidebook and Resource. New Jersey: John Wiley \& Son.

Xiong, Y., \& Quek, F. 2006. Hand Motion Gesture Frequency Properties and Multimodal Discourse Analysis, 69(3), 353-371. https://doi.org/10.1007/s11263-006-8112-5 